\title{
Evaluation the Factors Leading to Poverty Issue in Central Highlands of Vietnam
}

\author{
Tran Thi Giang1,2, Guohua Wang1, Danping Yan' \\ ${ }^{1}$ College of Public Administration, Huazhong University of Science and Technology, Wuhan City, China \\ ${ }^{2}$ College of Economics, Hue University, Hue City, Vietnam \\ Email: gianghce@yahoo.com.vn
}

Received 15 March 2014; revised 1 April 2014; accepted 10 April 2014

Copyright (C) 2014 by authors and Scientific Research Publishing Inc.

This work is licensed under the Creative Commons Attribution International License (CC BY).

http://creativecommons.org/licenses/by/4.0/

(c) (i) Open Access

\begin{abstract}
This paper focuses on examining the key factors that affect poor households in the Central Highlands by using the Ordinary Least Square (OLS) methods to analyze the Vietnam Living Standard Survey (VLSS) in 2008 panel dataset. In the 597 surveyed households in the Central Highlands, we selected 95 poor households to make research group. The empirical findings indicate that income per capita of poor households has been affected by many factors in which the strongest impact is from education level, size of households and marital status. Furthermore, the empirical study shows that most poor households in this research are ethnic minorities with large scale, low level of education and occupational skills.
\end{abstract}

\section{Keywords}

Poverty, Factors, Poor Households, Central Highland of Vietnam

\section{Introduction}

Poverty is a global problem. There is about $1 / 5$ of the world's population living in absolute poverty, about 2.5 billion people worldwide still live with an income less than 2 USD/person/day and this poverty situation has been almost unchanged between 1981 and 2005 [1]. The poverty rate in the Central Highlands is 24.1\%, which nearly doubles the national average and the poor households (HH) account for more than $21 \%$ of the country's poor people [2]. Therefore, Central Highlands is considered one of the poorest regions in Vietnam.

With a large percentage of the population living in extreme poverty, the Central Highlands may face difficulties to achieve the objectives of socio-economic development as well as to set out the millennium goals in poverty reduction. To ensure effective poverty reduction, it is necessary to understand the causes of the poverty situation in the Central Highlands. According to Imai and Gaiha [3], factors such as the household composition, education, landholding, and location are important determinants of the expenditure and poverty because poor 
households have low levels of educational attainment, insufficient and unstable employment. Besides, household size is an important "denominator" affecting the median income per household member. Large-scale households have high dependency ratios and vice versa, this condition indicates an unreasonable distribution of labors which contributes to poverty in households. In addition, Justino and Litchfield [4] and Tuan [5] found that the economic reforms have not helped some households escape from poverty, typically households living in remote areas or minority ethnic region where the main income comes from the agriculture sector. In addition, ethnic minority groups are not only poorer but also more vulnerable to various shocks than the majority groups.

In order to find out answers for the causes of poverty of households in the Central Highland, this paper attempts to explore two research questions as follows: (1) What are the characteristics of poor households in the Central Highlands? (2) What factors will affect the poor households in the Central Highlands? Which factors are the most influential?

In this paper, solving the problems is based on the logistic regression analysis method and using dataset from Vietnam Living Standard Survey in 2008 conducted by General Statistic Office (GSO).

\section{Overview of Poverty in Central Highland}

\subsection{Definition and Measurement of Poverty}

\subsubsection{Definition of Poverty}

Currently due to the development of world economy, poverty perspective can be understood by the different approaches:

In the official document of the Comprehensive Poverty Reduction and Growth Strategy (CPRGS), the government of Vietnam accepts the definition of poverty introduced by the Asia-Pacific Conference on Poverty Reduction organized by ESCAP in Bangkok, Thailand in September 1993. Poverty consists of absolute poverty and relative poverty.

Absolute poverty "is a situation in which a proportion of the population does not enjoy the satisfaction of basic human needs that have been recognized by the society depending on the level of economic and social development and local customs and practices."

Relative poverty "is a situation in which a proportion of the population living below the community average".

Absolute poverty lines have dominated past practice in some rich countries and in most developing countries including Vietnam. By this view, the poverty line is intended to have constant real value [6].

\subsubsection{Measurement of Poverty}

Presently, there are two parallel methods of measuring poverty in Vietnam; it included International Poverty Line Measurement Method and National Poverty Line Measurement Method [5].

International Poverty Line Measurement Method: This method to define the poverty lines based on international standards was developed by the General Statistical Office (GSO) with support from the World Bank and was used since the first Viet Nam Living Standards Surveys in 1993.

National Poverty Line Measurement Method: This method developed by Ministry of Labour, Invalids and Social Affairs (MOLISA) of Vietnam is based on the level of the economy and the rate of economic growth, the financial resources committed for poverty reduction for each period of time, and actual living standards of Vietnamese in specific regions. The welfare indicator is then measured by per capita income adjusted for regional differences by expressing in terms of the number of $\mathrm{kg}$ of rice.

In fact, these two methods are moving towards harmonizing. The most currently revised poverty lines of MOLISA was also based on consumption needs using expenditure of households with a basket of around 40 products to ensure the average $2100 \mathrm{Kcal}$ daily calorie intake per capita as recommended by the World Bank as well as some other nonfood items.

\subsection{Poverty in Central Highland}

Although policies to reduce poverty have been put into practice, there are still many households living in poverty in the Central Highlands after 25 years of innovation.

Table 1 shows that: All Central Highlands general poverty rate was $45.35 \%$ in 1996 and $24.1 \%$ in 2008, then down to $22.2 \%$ in 2010 according to new poverty standards. Poverty alleviation in the Central Highlands provinces 
was still difficult to achieve. So far, the general poverty rate in the region was still over $20 \%$. For instance, the general poverty rate was $21.96 \%$ in Kon Tum, $18.12 \%$ in Gia Lai, 15\% in Dak Lak, 16.58\% in Dak Nong, and $13.22 \%$ in Lam Dong in 2008. The rich and poor gap was larger, the gap among provinces with highest poverty rates was nearly two times of that among provinces with lowest poverty rate. Some ethnic minorities experienced higher poverty rates from $27 \%$ to $40 \%$ and the life of the households living in remote areas was more difficult. Each year hundreds of thousands of ethnic minority households still suffer hunger.

Besides, the poverty rate in the regions had significant differences. Table 2 pointed out that Northern midlands and mountain areas and the Central Highlands are two regions with highest poverty rate in the country. Compared with regions with lowest poverty rate, the poverty rate in Central Highlands nearly doubles the rate of poverty in the country. Such differences in poverty rates in the regions indicate that the ability to rise is different in different regions. There is rapid reduction in poverty in regions where there are rapid growth conditions.

\section{Materials and Methods}

\subsection{Methods}

The method for identifying the leading contributing factor in poverty in Central Highland was Ordinary Least Square (OLS) to estimate Vietnam Living Standard Survey in 2008 panel dataset conducted by the General Statistic Office (GSO). With the total number of households surveyed were 95 poor in Central Highland. Logistic regression analysis allowed for the simultaneous control of the independent variables. This technique was used to determine which independent variable had the greatest impact on the dependent variable. The Eviews computer software was used in this study.

Table 1. General poverty rate and poor households in Central Highlands.

\begin{tabular}{ccccccc}
\hline \multirow{2}{*}{ Year } & \multicolumn{2}{c}{2006} & 2008 & 2010 \\
\cline { 2 - 7 } & $\begin{array}{c}\text { Poor HH } \\
\text { (thous, pers) }\end{array}$ & $\begin{array}{c}\text { General poverty } \\
\text { rate (\%) }\end{array}$ & $\begin{array}{c}\text { Poor HH } \\
\text { (thous, pers) }\end{array}$ & $\begin{array}{c}\text { General poverty rate } \\
\text { (\%) }\end{array}$ & $\begin{array}{c}\text { Poor HH } \\
\text { (thous, pers) }\end{array}$ & $\begin{array}{c}\text { General poverty rate } \\
\text { (\%) }\end{array}$ \\
\hline Whole country & 15079.6 & - & 13,194 & 14.5 & 11648.3 & - \\
Central Hingland & 1173 & 28.6 & 1067.1 & 24.1 & 1165.3 & 22.2 \\
Kon Tum & 123.7 & 31.38 & 112.3 & 21.96 & 141.4 & 33.36 \\
Gia Lai Province & 320.5 & 27.2 & 296.6 & 18.12 & 337.4 & 27.56 \\
Dak Lak & 407.7 & 23.28 & 365.3 & 15 & 384.2 & 20.82 \\
Dak Nong & 111.6 & - & 107.2 & 16.58 & 144.5 & 23.35 \\
Lam Dong & 209.5 & 18.32 & 185.7 & 13.22 & 157.8 & 13.39 \\
\hline
\end{tabular}

Source: GSO (VLSS 2006, 2008, 2010).

Table 2. Poor households and poverty rate by regions.

\begin{tabular}{ccccc}
\hline \multirow{2}{*}{ Year } & \multicolumn{3}{c}{2006} & \multicolumn{2}{c}{2008} \\
\cline { 2 - 5 } & Poor HH (thous, pers) & Poverty Rate (\%) & Poor HH (thous, pers) & Poverty rate (\%) \\
\hline Whole country & 15079.6 & 15.5 & 13,194 & 13.4 \\
Red River Delta & 1690.167 & 10.0 & 1473.638 & 8.6 \\
Northern midlands and mountain areas & 1892.6 & 27.5 & 1674.738 & 25.1 \\
North Central and Central coastal areas & 5133.535 & 22.2 & 4718.273 & 19.2 \\
Central Highlands & 1173 & 24.0 & 10,671 & 21 \\
South East & 3077.472 & 3.1 & 2873.556 & 2.5 \\
Mekong River Delta & 2540.97 & 13.0 & 4283.275 & 11.4 \\
\hline
\end{tabular}

Source: GSO (VLSS 2006, 2008). 


\subsection{Data Collection}

This study used quantitative existing data from the Vietnam Living Standard Survey in 2008. The VLSS 2008 was conducted nation-wide with a sample size of 45,945 households, in which 9189 households were surveyed on both income and expenditure in 3063 communes/wards which were representative at national, regional, urban, rural and provincial levels. The survey collected information through face-to-face interviews conducted by interviewers with household heads and key commune officials in communes. There were 597 households surveyed in Central Highlands, including 110 poor households in five provinces. To be specific, 24 households in Kon Tum, 25 households in Dak Nong, 32 household in Gia Lai, 10 households in Dak Lak and 19 households in Lam Dong. The sample of this survey was randomly selected and based on Vietnam's poverty line which is 200 thousand VND/person/month in rural areas, 260 thousand VND/person/month in urban areas in 2006. In contrast, international poverty line is $\$ 1$ person/day (approximately equivalent to 500 thousand/month). This topic eliminates poor households with income and expenditure per capita beyond the poverty threshold. On that basis, the authors selected 95 poor households (in which, 27 poor households in urban area and 68 poor households in rural area) according to local classification for research.

\subsection{Data Processing: Model and Variables}

The effects of the following factors on poverty status were analyzed, including ethnic group, educational attainment, age, household size, gender, area, occupation, married status and expenditure for health. These factors were chosen because the reviewed literatures argued they increased the likelihood of the poverty of households. Definitions of variables are presented in the Table 3.

$$
\text { Model: } Y=\beta_{0}+\beta_{1} X_{1}+\beta_{2} X_{2}+\beta_{n-1} X_{n-1} \cdots+\beta_{n}\left(X_{n-1} * X_{n}\right)+\varepsilon_{i}
$$

In which: $X$ : Independent variable; $\beta_{0}$ : is the intercept; $\beta_{i}$ : is the correlation coefficient; $\varepsilon_{i}$ : is the error term or disturbance. $Y$ : Dependent variable: Refers to an income per capita of the heads of the poor $\mathrm{HH}=$ income per capita from (Salaries and wages + Farming activities + Livestock + Hunting, trapping, animals and birds domesticated + Agricultural services + Forestry + Fishing + Non-agricultural, Non-forestry services, processed agricultural, forestry, fisheries products + Other income).

\section{Data Analysis and Findings}

\subsection{Characteristics of Poor Households in the Central Highlands}

The data collected from 95 poor households in Central Highland have been analyzed by using the statistical,

Table 3. Definition of variables.

\begin{tabular}{|c|c|c|}
\hline Variables & Definition & Abbreviations \\
\hline \multicolumn{3}{|l|}{ Dependent Variable: } \\
\hline Poverty status & Refers to an income per capita of the heads of the poor $\mathrm{HH}$ & POS \\
\hline \multicolumn{3}{|l|}{ Independent Variables: } \\
\hline Education (dummy) & $\begin{array}{l}\text { Refers to the educational background of the heads of the poor } \mathrm{HH} \text { : If the educational } \\
\text { attainment of the household's head was equal or higher than upper secondary school level: } \\
\text { EDUC = } 1 \text {; otherwise, EDUC = } 0 \text {. }\end{array}$ & EDUC \\
\hline Ethnic group (dummy) & $\begin{array}{l}\text { Refers to Ethnic group: if the head of poor HH belongs to "Kinh” ethnicity, ETH = 1; } \\
\text { otherwise, ETH = } 0 \text {. }\end{array}$ & ETH \\
\hline Area (dummy) & $\begin{array}{l}\text { Refers to the living area in Rural or Urban: if the head of poor HH lives in Urban; } \\
\text { AREA = 1, lives in Rural, AREA = 0). }\end{array}$ & AREA \\
\hline Gender (dummy) & Refers to male or female: if the head of poor HH is Male: GDER = 1, Female; GDER = 0 . & GDER \\
\hline Age & Refers to the actual age of the head in poor $\mathrm{HH}$ & AGE \\
\hline Occupation (dummy) & Refers to job type: if the head of poor HH is skilled labor: OCC = 1 ; otherwise, OCC $=0$. & OCC \\
\hline Household size & Refers to the number of people living together in one house & HS \\
\hline Married status (dummy) & If poor HH has both husband and wife; MS = 1, otherwise, MS = 0. & MS \\
\hline Expenditure for health & The number of money of poor $\mathrm{HH}$ is spent on health in 12 months & EXH \\
\hline
\end{tabular}


description and comparison method. We found that the poverty situation of households in the Central Highlands region was due to the following main factors:

Land area per capita/poor household is 5,605,526 $\mathrm{m}^{2}$, most of which is annual crop land. The latter accounts for $76.3 \%$ of the total land area (average rice land area per poor household accounts for $31.4 \%$; types of food crops such as cassava, potatoes, maize, beans account for $50.6 \%$ of the total annual crop land). Perennial crop land accounts for $20.45 \%$ of total land area (in which coffee, rubber account for $74.3 \%$ of the total perennial crop land). Water surface accounts for $0.94 \%$ of the total land area. The remaining is residential land. Income from livestock per capita/household/year is 2178.96 thousand VND, including income from poultry (18\%); income from pig, cattle (78.8\%); income from hunting, trapping, animals and birds domestication $(1.14 \%)$. The rest is collected from other livestock operations.

Besides, most of the poor households are large size (the average household size is 5.18 people) and concentrate mainly on ethnic minority households, which account for $62.11 \%$ of the households surveyed. This will increase the burden of spending and hence reduce the accumulation accounts. Therefore, the escape from poverty will come to a deadlock; besides, the proportion of dependents in poor households is very high (average number of dependents/household is 1.67 people). The dependents account for over $32 \%$ of the total members of the households. The dependent rate in rural areas is $33 \%$, whereas it is $27.3 \%$ in urban areas. It is also one of the important and decisive factors of poverty of the people. Because it will increase the burden on the main workers in the family, the labor shortage has led to insufficient income to meet living expenses. Therefore, the necessary needs of most children have not been satisfied fully yet, their lives will fall into the poverty; in addition, the number of poor households with female heads account for a relatively large proportion (15.14\%). It is more difficult for women to find work than men, their incomes are often low and their work seems not stable because they are very vulnerable.

In addition, the main occupation of the majority of labors in poor households is unskilled (71.59\%) and their work has concentrated on the areas of agriculture and forestry, hence their income is very low. Expenditure of the poor households has been tightened, mostly spent on food (42.56\%). Although the fact shows the high proportion of expenditure on food, the quantity and quality of their meals have not been guaranteed. The regular food shortages and loss of meals have affected their health and incomes. Thus, it is difficult for the poor people to escape the vicious cycle of poverty. Moreover, most of the heads of poor households often have lower education (the proportion of households without any degree was very high (48.85\%)). Because of the lack of professional skills, they did not have many opportunities to earn good high-paying jobs, so the poverty would be definitely inevitable and the gap between the rich and the poor has actually not been narrowing. In addition, the poor have limited access to health services than the non-poor (the rate of using of health services per household in the 12 months of rich households was nearly 1.5, higher than that of the poor households). This will reduce the possibility to improve health; they are more susceptible to illness and have few chances of treatment. It will cause a negative impact on employment and income as well as increasing the poverty of the households surveyed.

\subsection{Results of Experimental Study}

4.2.1. Factors Have Affected Incomes per Capita of Poor Households in the Central Highland Region Basing on the regression results in Table 4, it shows that both GDER and AGE variables have a positive impact on household incomes besides EXH variable, but not statistically significant. The remaining variables have positive significances in explaining income per capita of poor households in this area. Regression coefficient of ETH variable is 6.158154 at $10 \%$ statistical significance level, this indicates that income per capita of ethnic majority households has been affected more positively than that of ethnic minority households by 6.158154 Vietnamese Dong (VND). This result is consistent with the fact that Kinh ethnic people are able to improve their lives because of their good educational background.

EDUC regression coefficient is 6137.863 at $5 \%$ statistical significance level. The empirical evidence shows that households with higher education level have higher income per capita than other households by 6137.863 VND. Similarly, the influence of the residence on the average household income is also a factor mentioned by many previous studies, it is seen as an advantage of geographical position, AREA variable has positively impacted household incomes. The result shows that households living in urban areas have higher incomes per capita than households living in rural areas by 147.0203 VND at 5\% statistical significance level.

Among the factors affecting income per capita of poor households in the Central Highlands, the household's 
Table 4. Impact of factors on income per capita of poor households.

\begin{tabular}{|c|c|c|c|}
\hline Independent Variables & Coefficient & t-Statistic & P-Value \\
\hline $\mathrm{C}$ & 33584.58 & 3.202141 & 0.0019 \\
\hline EXH & 0.344742 & 1.728829 & 0.9874 \\
\hline ETH & 6.158154 & 0.117525 & 0.0567 \\
\hline AREA & 147.0203 & 2.573175 & 0.0118 \\
\hline GDER & 97.38722 & 1.845401 & 0.1683 \\
\hline AGE & 2.079413 & 1.774727 & 0.2194 \\
\hline HS & -3011.827 & 5.025894 & 0.0000 \\
\hline OCC & 86.55155 & 1.907268 & 0.0597 \\
\hline MS & 11590.61 & 3.384870 & 0.0011 \\
\hline EDUC & 6137.8630 & 2.187240 & 0.0314 \\
\hline R-squared & 0.383803 & & \\
\hline Adjusted R-squared & 0.318558 & & \\
\hline S.E. of regression & 181.6733 & & \\
\hline Sum squared resid & 2805440 . & & \\
\hline Log likelihood & -623.7259 & & \\
\hline F-statistic & 1.992810 & & \\
\hline Prob(F-statistic) & 0.049893 & & \\
\hline
\end{tabular}

Source: Author's calculations based on VLSS in 2008.

size (HS) variable has the strongest and most significant impact. According to the demography, the size of households includes the number of employees and dependents. The size of households has a negative impact on their incomes. Regression coefficient of HS variable was 3011.827, at 1\% statistical significance level, because the number of dependents in poor households is very high. Marital status (MS) and career skills (OCC) have also positive influences on incomes per capita, from regression coefficients, we find that households with both husband and wife have higher incomes per capita than households with either husband or wife by 11590.61 VND, at $1 \%$ statistical significance level. This evidence shows the roles of household head in creating and improving income for his or her life, which have positive impacts on the household's income per capita. Professional skills are considered indispensable elements toward any works in the life. Finding proves that households with more skilled labor have increased income per capita to 86.6 VND in comparison with others, at $10 \%$ statistical significance level.

\subsubsection{The Simultaneous Impacts of These Factors on Income per Capita of Poor Households in the Central Highlands Region}

In Table 5, we can see the separate impact of each factor on household incomes, although most of the factors have explained positively and significantly. In order to evaluate the simultaneous effects of these factors on the average household incomes, based on model1, the models were extended to test hypotheses in order to clarify this problem further.

The simultaneous impacts of education and household size on incomes per capita of poor $\mathrm{HH}$

When considering the interaction of the factors to incomes per capita of poor households in the study area, we incorporated the interaction of the variables, which are statistically significant. Looking at Table 5, we find the regression coefficient of EDUC variable has an opposite impact (at 1\% statistical significance level) on the income per capita of poor households. This seems not to be real because the higher level of education often has the strong, positive influence on income per capita of the households. However, we believe that reality is not so, 
Table 5. The impacts of household size on income per capita of poor households.

\begin{tabular}{cccc}
\hline Independent Variables & Coefficient & t-Statistic & P-Value \\
EDUC & 18436.83 & 10.13093 & 0.0000 \\
AREA & -14683.91 & -3.678850 & 0.0004 \\
EDUC*HS & 8668.547 & 2.667375 & 0.0091 \\
R-squared & 3418.860 & 5.313575 & 0000 \\
Adjusted R-squared & 0.335853 & & \\
S.E. of regression & 0.285446 & & \\
Sum squared resid & 10780.52 & & \\
Log likelihood & $1.05 \mathrm{E}+10$ & & \\
F-statistic & -1014.353 & 10.38765 & \\
Prob (F-statistic) & 0.000001 & &
\end{tabular}

Source: Author's calculations based on VLSS in 2008.

only the education factor can not explain incomes per capita of poor households in this area. To test this, we considered the combined effects of (EDUC*HS) variables, with the expectation that the households with higher education level combining with the size of households have had a positive impact on the average income of households. From the regression results, we find that all poor households with the high level of education and more family labors have increased their incomes per capita to 3418.860 VND. This is supported by Imai and Gaiha [3]. They stated that the household composition and education are important determinants of the poverty because poor households have low levels of educational attainment and unstable employment. Besides, household size is an important factor affecting the median income per household member.

Impacts of career skills, region and gender on the incomes per capita of poor households in the Central Highlands

Table 6 shows that the OCC variable has had an opposite impact on the income per capita and that professional skills cannot sufficiently explain the income per capita. To assess the impacts of occupational skills and ethnic composition, we hypothesize that, "whether or not the income per capital of Kinh ethnic households with skilled labors was higher than that of ethnic minority households with simple labors?” From the regression results, we can find that Kinh ethnic households with occupational skills have increased the average income of households to $0.389705 \mathrm{VND}$, compared with ethnic minority households with unskilled labor. So, professional skills combining with Kinh ethnic groups have a positive impact on their incomes, but this effect is not strong. This shows that the programs to improve professional skills for the poor such as the production of technical training are necessary to enable them to escape poverty. By testing hypotheses "whether or not the income per capita of poor households living in urban areas having higher education levels was higher than that of poor households living in rural with lower education levels?"

To answer the hypothesis mentioned above, (AREA*EDUC) variable is added into the model. Results show that poor households in urban areas with higher education level have increased their incomes per capita to 7347.737 VND, compared with poor households living in rural with lower education level. However, the impact to their incomes is not very strong. This finding is supported by previous research, which said that "poor households living in remote areas or minority ethnic region where the main income derives from the agriculture sector to difficult to escape from poverty" [4]. In addition, the empirical results show income per capita of the maleheaded poor household increased to 101.6631 VND in comparison with the income of female-headed poor households, at $10 \%$ statistical significance. This is supported by Rajaram [7] and Koster [8] as authors stated that "exist significant differences between the living standards of households headed by male compared with households headed by female."

Impact of age, career skills and household size on the income per capita of poor $\mathrm{HH}$ 
Table 6. Impacts of career skills, regional and gender on the income per capita.

\begin{tabular}{cccc}
\hline Independent Variables & Coefficient & t-Statistic & P-Value \\
\hline C & 16643.10 & 5.342473 & 0.0000 \\
OCC & -7.927246 & -0.002866 & 0.9977 \\
OCC*ETH & 0.389705 & 1.974428 & 0.0514 \\
AREA*EDUC & 7347.737 & 1.792682 & 0.0764 \\
GDER*AGE & 101.6631 & 1.715253 & 0.0897 \\
R-squared & 0.528412 & & \\
Adjusted R-squared & 0.499678 & & \\
S.E. of regression & 12168.04 & & \\
Sum squared resid & $1.33 \mathrm{E}+10$ & & \\
Log likelihood & -1025.855 & & \\
F-statistic & 3.314945 & & \\
Prob (F-statistic) & 0.013968 & & \\
\hline
\end{tabular}

Source: Author's calculations based on VLSS in 2008.

From the results of regression, we can find that the AGE factor alone has a negative impact on the average income of households of about -637.4073 VND. The higher age of head in households has stronger negative impact on the families' income. Regression coefficient of HS variable shows that the more members families have, the stronger negative impacts on their incomes. The regression coefficient of (AGE*HS) variable is -82.24215 , at $10 \%$ statistical significance level, so we see that age and size of households have had negative impacts on their incomes. The high age of head in households and more members in their families have made the household incomes per capita fall. As we analyzed above, the age factor has a direct effect on incomes, the higher the age is, the greater the effect is, it shows the roles of household head in generating incomes and in taking care of their families. This finding is supported by previous research which argued that "age (older versus younger) had a statistically significant effect on poverty status” [9].

However, when considering the households and professional skills, we can see the households with professionally skilled labors have generated higher incomes per capita than households with unskilled labors by 65.3 VND. Because skill labor can create stable incomes and these incomes have tended to increase in all timework of households. Thus, professional skill factor has a strong and positive impact on incomes per capita of the households.

To assess the roles of households' professional skills in improving and generating income for their families, HS and OCC variable are included in the model, the empirical results are presented in Table 7, which shows that households with professional skills have generated higher incomes than households without career skills or unskilled labors by 168.3978 VND when other factors are constant. Because the household head with professional skills can convey the knowledge to other members or train them. Thus, they have created many advantages in raising income and in improving their livings.

Impacts of married status, regional and ethnic component on the income per capital of poor household in Central Highland

Regional factor has important implications in generating income for households. Within this study, regional variable is considered in Urban and Rural areas. In order to assess this effect, this research is based on the hypothesis "whether or not the marital status and geographical location have affected incomes per capita of poor households? In addition, "whether or not there are the effects of ethnic composition, geographical location and the size of households on incomes per capita of poor households in the Central Highland?”

In order to answer the questions, the regression models were built and tested hypotheses. Regression results in Table 8 show that when other conditions are constant, income per capita of Kinh ethnic households are higher than the income per capita of minority households by 22867.54 VND. Many studies have shown that these 
Table 7. Impact of age, career skills and household size on the income per capita of poor HH.

\begin{tabular}{cccc}
\hline Independent Variables & Coefficient & t-Statistic & P-Value \\
C & 31052.45 & 1.863474 & 0.0658 \\
AGE & -637.4073 & -1.885669 & 0.0027 \\
MS & 10394.29 & 0.749410 & 0.0455 \\
HS & -5649.442 & -2.187619 & 0.0314 \\
AGE*OCC & 65.26788 & 0.599683 & 0.0055 \\
HS*AGE & -82.24215 & -0.303149 & 0.0762 \\
OCC*HS & 168.3978 & 0.195469 & 0.0845 \\
R-squared & 0.438156 & & \\
Adjusted R-squared & 0.385892 & & \\
S.E. of regression & 9994.123 & & \\
Sum squared resid & $8.59 \mathrm{E}+09$ & & \\
Log likelihood & -1004.998 & & \\
F-statistic & 8.383430 & 0.000000 & \\
Prob (F-statistic) & & &
\end{tabular}

Source: Author's calculations based on VLSS in 2008.

Table 8. Effects of married status, regional and ethnic component on the income per capita of poor HH.

\begin{tabular}{cccc}
\hline Independent Variables & Coefficient & t-Statistic & P-Value \\
\hline C & 19371.57 & 8.651505 & 0.0000 \\
ETH & 22867.54 & 3.666341 & 0.0004 \\
AREA & 11440.79 & 1.909228 & 0.0595 \\
ETH*HS & 4955.354 & 3.672086 & 0.0004 \\
MS*AREA & 10837.04 & 3.079800 & 0.0028 \\
AREA*HS & 170.6195 & 3.390534 & 0.0011 \\
R-squared & 0.234262 & & \\
Adjusted R-squared & 0.191243 & & \\
S.E. of regression & 11469.15 & & \\
Sum squared resid & $1.17 \mathrm{E}+10$ & & \\
Log likelihood & -1019.705 & & \\
F-statistic & 5.445560 & 0.000204 & \\
Prob (F-statistic) & & \\
\hline
\end{tabular}

Source: Author's calculations based on VLSS in 2008.

disparities in living standards between ethnic minorities and ethnic majorities groups are confirmed in a number of other qualitative and quantitative studies [10]-[13]. Similarly, AREA variable also has a positive impact on income per capita of the households. Income per capita of households living in Urban area are higher than that of households living in Rural and Mountainous areas by 11440.79. This finding is supported by previous research which argued that households in upland and mountain areas where access to infrastructure or health and 
educational facilities is limited are much poorer than the households in urban area [3] [12]. However, when combining the interaction term of ETH and HS variables, we explore that the regression coefficient of (ETH*HS) variable is 4955.354 , at $1 \%$ statistical significance level. Thus, the slope coefficient decreased compared with the before combining is 17912.19 VND. This means that size of Kinh ethnic households has affected income per capita more strongly than the size of ethnic minority households has. The regression coefficient of (AREA*MS) variable is 10837.04, at $1 \%$ statistical significance level. This shows that there are four possibilities, but the most reasonable possibility is that households with both husband and wife living in urban area have had stronger impacts on their incomes per capita than other cases by 10837.04 VND when other factors were constant. This is supported by Trahan [9], as he stated that "Marital status had an even greater statistically significant effect on poverty status. Only $6.4 \%$ of married women were poor and $38.0 \%$ of non-married women were poor."

\section{Conclusions}

The present study found that: The factors of education (EDUC), marital status (MS) have positive impacts, the size of households' structure (HS) has a negative impact, but both three factors have strong influences and high statistical significance. Factors such as ethnic groups (ETH), occupation (OCC) and area (AREA) have positive impacts on income per capita of the poor households but with milder effects and they are also statistically significant. Meanwhile, factors such as health spending (EXH), age of the household head (AGE) and gender (GDER) were not statistically significant.

When combining variables, we find that: The Kinh ethnic poor households living in urban area and small household size have had higher incomes per capita than households living in rural and big household size. In addition, Kinh ethnic households with both husband and wife have higher income per capita than minority ethnic households or households with male or female head. Finally, poor households with higher education level and skill labour have had higher incomes per capita than poor households with lower education levels and unskilled labour.

Therefore, it is imperative that government policies concentrate on not just enhancing the endowments of the minorities but also seeking to reduce the disparities in the returns to such endowments between the minorities and the majority. Policy priorities from this perspective are to improve the quality of education that minorities receive, reduce the scale of the households, create jobs to increase income for minority households and poor households in rural area, and build better infrastructure in remote areas to promote easier market access and better livelihood prospects for them. In addition, social workers can assist impoverished male or female head in households with a variety of recourses such as affordable housing, food assistance, and financial benefits such as Social Security Supplemental Insurance.

\section{References}

[1] Chen, S. and Ravallion, M. (2008) The Developing World Is Poorer than We Thought, But No Less Successful in the Fight against Poverty.

[2] Statistical Publishing House (2008) Statistical Yearbook of Vietnam. Hanoi.

[3] Imai, K. and Gaiha, R. (2007) Poverty, Inequality and Ethnic Minorities in Vietnam. BWPI, Manchester.

[4] Justino, P. and Litchfield, J. (2002) Poverty Dynamics in Rural Vietnam: Winners and Losers during Reform. In: 27th Biannual Conference of the IARIW, Globalisation and Poverty, Stockholm, 42.

[5] Anh-Tuan, P. (2008) Viet Nam Country Case Study. Background Paper for the Chronic Poverty Report, Chronic Poverty Research Centre.

[6] Shaohua, C. and Ravallion, M. (2012) More Relatively-Poor People in a Less Absolutely-Poor World. Policy Research Working Paper, The World Bank, Washington DC, 6114.

[7] Rajaram, R. (2009) Female-Headed Households and Poverty: Evidence from the National Family Health Survey. In: 3rd Southeastern International/Development Economics Workshop—Agenda \& Papers, Atlanta, 4 December 2009.

[8] Koster, M. (2008) Linking Poverty and Household Headship in Post-Genocide Rwanda. In: The HiCN’s 4th Annual Workshop, Yale University, New Haven, 26p.

[9] Trahan, D.L. (2009) Women in Poverty. California State University, Long Beach.

[10] Van Long, H. and Yabe, M. (2011) Unequal Regional Development in Rural Vietnam: Spatial Disparities And Policy Considerations. In 2nd International Conference on Business and Economic Research (2nd ICBER 2011), Langkawi, 14-16 March 2011, Conference Master Resources. 
[11] Baulch, B., et al. (2010) Ethnic Minority Poverty in Vietnam. Chronic Poverty Research Centre (CPRC).

[12] Van de Walle, D. and Gunewardena, D. (2001) Sources of Ethnic Inequality in Viet Nam. Journal of Development Economics, 65, 177-207. http://dx.doi.org/10.1016/S0304-3878(01)00133-X

[13] Kang, W. (2009) Pro-Poor Growth, Poverty, and Inequality in Rural Vietnam: Welfare Gap between the Ethnic Majority and Minority. The University of Manchester, Manchester. 